\title{
Early historic human remains from the Hasekouji-Shuhen site in Kamakura, Japan
}

\author{
HIROFUMI MATSUMURA ${ }^{1 *}$, MINORU YONEDA $^{2}$, HIDEAKI SHUDAI $^{3}$ \\ ${ }^{1}$ Department of Anatomy, Sapporo Medical University, S1W17, Sapporo, 060-8556 Japan \\ ${ }^{2}$ Department of Integrated Biosciences, Graduate School of Frontier Science, The University of Tokyo, Japan \\ ${ }^{3}$ Faculty of Literature, Tsurumi University, Kanagawa, Japan
}

Received 5 April 2005; accepted 16 February 2006

\begin{abstract}
Eight human skeletons in a good state of preservation have been recovered from excavations at the Hasekouji-Shuhen site in Kamakura city, Kanto region, Japan. We conducted AMS radiocarbon dating that revealed the skeletons to belong to the early historic Asuka, Nara, and early Heian periods (circa 670-970 calAD). In terms of their cranial, dental, and limb bone measurements, the Hasekouji-Shuhen skeletons exhibit morphological characteristics that show affinities with the earlier Yayoi series, which are generally considered to represent immigrant populations from the Asian continent. Furthermore, an early indication of dolichocephalization was observed in these early historic people, a trait which became more pronounced in later medieval times. Three adult males have scars that may have been caused by assaults with a spear or a sword-like weapon. One male individual exhibits skeletal abnormalities including multiple cartilaginous exostosis.
\end{abstract}

Key words: Hasekouji-Shuhen site, AMS dating, Asuka-Nara-Heian period, dolichocephalization, trauma

\section{Introduction}

The Hasekouji-Shuhen site is located at Yuigahama-3chome in Kamakura city, in the southwestern coastal area of the Kanto region, Japan (Figure 1). The site was formed on a sand dune, $10.6 \mathrm{~m}$ above sea level. The excavation of this site was undertaken by the Togoku Institute of History and Archaeology under the direction of one of the authors (H.S.) in 1998 (Shudai et al., 2002). An area of $722 \mathrm{~m}^{2}$ was excavated, revealing five cultural layers.

The first cultural level is situated at a depth of about $0.5-$ $1.7 \mathrm{~m}$, and revealed early modern agricultural features, trails, and pots. The second and third levels are of the medieval period. Typical ceramics and bronze coins made during the 14th and 15th centuries (second level) and 13th and 14th centuries (third level) were recovered at depths of about 1.7$2.2 \mathrm{~m}$ and $2.2-2.8 \mathrm{~m}$, respectively. The fourth level, at a depth of about $2.8-4 \mathrm{~m}$, is characterized by an abundance of pots produced between the 7 th and 10th centuries, corresponding to the early historic Asuka, Nara, and Heian periods. The fifth level, situated below about $4 \mathrm{~m}$ depth, was formed naturally and does not contain any artifacts.

Inhumation burials were found in a white sand layer in the fifth level. Fission track dating indicated an age of 250-350 $\mathrm{AD}$ for the volcanic pumice that covers the fifth level, and about $1 \mathrm{AD}$ for the volcanic conglomerate collected from the fifth level. This suggested that the layer was formed during

* Corresponding author. e-mail: hiromura@sapmed.ac.jp phone: +81-11-611-2111; fax: +81-11-618-4288

Published online 1 June 2006

in J-STAGE (www.jstage.jst.go.jp) DOI: 10.1537/ase.050405 the Middle to Late Yayoi period (circa 300 BC-300 AD). Eleven human skeletons were unearthed from the fifth level but without any associated artifacts. Shudai et al. (2002) and Anezaki and Shudai (2001) reported that these human skeletal remains were buried during the Middle and Late Yayoi period or at least before the beginning of the protohistoric Kofun period (circa 300-500 AD).

However, the accuracy of the dates assigned to the human remains from the Hasekouji-Shuhen site is now in doubt. The layer containing the human skeletal remains lacks any cultural material and the stratigraphic relationship between the burial pits and the volcanic ash sampled for dating is unclear. In this study, we provide new radioisotopic dates,

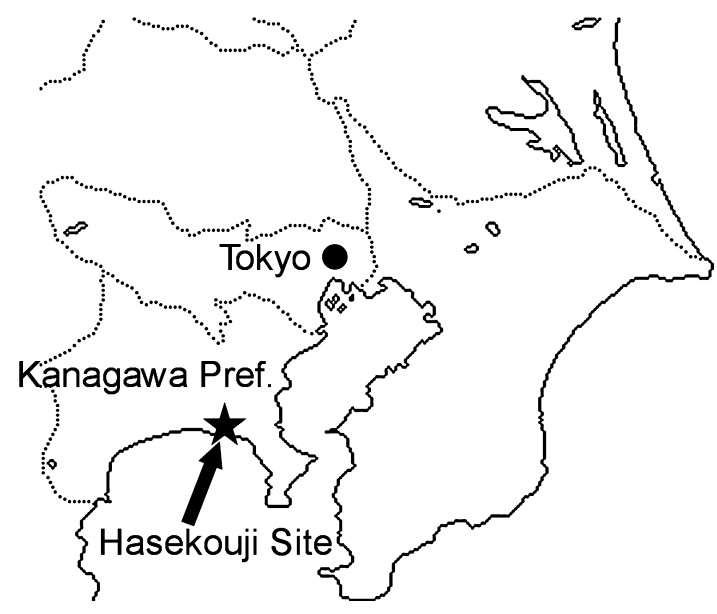

Figure 1. Map showing the location of the Hasekouji-Shuhen site. 
based on accelerator mass spectrometry (AMS) analysis, for the human skeletons from the Hasekouji-Shuhen site that suggest a somewhat later early historic age of the skeletons.

We also report on observations of the preservation and morphological features of the Hasekouji-Shuhen skeletons, including sex, estimates of age-at-death, and some paleopathological observations. Using skeletal and dental measurements recorded from these specimens, we further discuss some of the current models that have been proposed to explain the population history of the Japanese archipelago.

It is now widely accepted that there was a major influx of people immigrating from the East Asian continent into the Japanese archipelago during the Yayoi period (circa 800 BC-300 AD), and that those people then presumably interbred with the indigenous Jomon people (e.g. Kanaseki et al., 1960; Yamaguchi, 1985; Hanihara, 1987, 1991; Mizoguchi, 1988; Nakahashi et al., 1989; Dodo and Ishida 1990; Nakahashi, 1993; Matsumura, 2001). The immigrants with their advanced technology and culture continued to arrive in Japan from the East Asian continent throughout the protohistoric and early historic periods. These new immigrants are believed to have been responsible for establishing the imperial court in the Kinki district in western Japan, whose influence and power would eventually expand eastward. According to Hanihara's (1991) 'dual structural model', genetic influence stemming from the immigrants gradually spread throughout Japan, a process that continues to this day. Therefore, the nature and degree of influx of the immigrants during the Yayoi and early historic periods have been a crucial point of discussion in considering the population history of Japan. The skeletal and dental features of the HasekoujiShuhen skeletons provide an opportunity to see what, if any, the effects of this presumed immigration had on the protohistoric to early historic inhabitants of Japan.

A large number of medieval human skeletons of the Kamakura period (1192-1333 AD) have been excavated in Kamakura city, including those from the Zaimokuza (Suzuki, 1956), Gokurakuji, and Yuigahama sites (Hirata et al., 2002, 2004). Suzuki's (1956) study of diachronic change of Japanese skeletal morphology demonstrated that the medieval people had morphological peculiarities such as a dolichocranic cranium and alveolar prognathism, traits that are not characteristically seen in other Japanese skeletal remains from any time period. Specimens from the Hasekouji-Shuhen site, a site that predates the Kamakura period, are compared with the Kamakura period series in order to discuss possible temporal changes in skeletal morphology from pre-medieval times to the medieval period in the same region.

\section{Age of the Skeletons}

New radiocarbon dates for the human skeletal remains from the Hasekouji-Shuhen site were obtained by NIESTERRA, the accelerator facility of the Institute for Environmental Studies located at Tsukuba city, Japan (Yoneda et al., $2004)$. Stable carbon isotope ratios $\left(\delta^{13} \mathrm{C}\right.$ values $)$ and atomic $\mathrm{C} / \mathrm{N}$ ratios in collagen were measured by a mass spectrometer with an elemental analyzer (EA-IRMS). All dates were made on well-preserved human bones with good agreement of their $\mathrm{C} / \mathrm{N}$ ratio (between 2.9 and 3.5) to modern animal bones (DeNiro, 1985). The collagen content in bone was high enough to produce a reliable date (Table 1).

Table 1 shows Conventional Radiocarbon Ages (CRA) (Stuiver and Pollach, 1977) and $\delta^{13} \mathrm{C}$ values used for correcting fractionation of ${ }^{14} \mathrm{C}$ ratios. Some individuals show less negative $\delta^{13} \mathrm{C}$ values in collagen, suggesting the possibility that some amount of carbon in collagen might have originated from the marine reservoir. A correction must be made to account for the marine reservoir effect that is caused by the upwelling of ${ }^{14} \mathrm{C}$-depleted deep water. The percentage of marine carbon was estimated from a linear mixing model of typical $\delta^{13} \mathrm{C}$ values for marine and terrestrial food consumers between $-12.5 \%$ and $-21.0 \%$, re-spectively (Yoneda et al., 2002, 2005). A calibration curve is calculated by mixing terrestrial and marine samples depending on their marine carbon content. The calibrated ${ }^{14} \mathrm{C}$ ages were calculated by the OxCal program (version 3.9; Bronk Ramsey, 1995, 2001) based on dendrochronological and marine data sets, INTCAL98 and MARINE98 (Stuiver et al., 1986, 1998; Stuiver and Reimer, 1993).

The calibrated ages of 670-970 AD correspond to the Asuka, Nara, and early Heian periods (Table 2). Regional correction ( $\Delta \mathrm{R}$ value) for the marine reservoir effect was tentatively estimated to be null in this region, based on water mass in the Kuroshio current evaluated from a coral core in Okinawa prefecture (Hideshima et al., 2001).

\section{Description of the Human Remains}

Eleven individual skeletons were recovered from the

Table 1. Conventional ${ }^{14} \mathrm{C}$ ages, $\delta^{13} \mathrm{C}$ values and $\mathrm{C} / \mathrm{N}$ ratios of human collagen

\begin{tabular}{|c|c|c|c|c|}
\hline Sample & $\mathrm{C} / \mathrm{N}$ ratio & ${ }^{14} \mathrm{C}$ age (year BP) & $\delta^{13} \mathrm{C}(\%)$ & Lab. No. \\
\hline No. 1 & 2.88 & $1319 \pm 44$ & -18.3 & TERRA-081002a17 \\
\hline No. 2 & 3.08 & $1363 \pm 47$ & -16.1 & TERRA-081002a18 \\
\hline No. 3 & 2.98 & $1228 \pm 47$ & -19.2 & TERRA-081002a19 \\
\hline No. 4 & 2.95 & $1338 \pm 44$ & -18.6 & TERRA-081002a20 \\
\hline No. 5 & 3.06 & $1486 \pm 43$ & -17.4 & TERRA-081002a23 \\
\hline No. 6 & 2.96 & $1290 \pm 44$ & -17.8 & TERRA-081002a24 \\
\hline No. 7 & 2.97 & $1376 \pm 44$ & -18.5 & TERRA-081002a25 \\
\hline No. X & 2.98 & $1423 \pm 43$ & -17.4 & TERRA-081002a26 \\
\hline
\end{tabular}

Conventional ${ }^{14} \mathrm{C}$ ages (Stuiver and Pollach, 1977). 
Table 2. Contribution of carbon from the marine reservoir and calibrated ${ }^{14} \mathrm{C}$ ages correcting for the ${ }^{14} \mathrm{C}$ marine reservoir effect

\begin{tabular}{ccc}
\hline Sample & Marine $\%$ & Calibrated ${ }^{14} \mathrm{C}$ age (calAD) \\
\hline No. 1 & $32 \%$ & $720-900$ \\
No. 2 & $58 \%$ & $810-970$ \\
No. 3 & $21 \%$ & $780-970$ \\
No. 4 & $28 \%$ & $710-870$ \\
No. 5 & $42 \%$ & $650-770$ \\
No. 6 & $38 \%$ & $810-970$ \\
No. 7 & $29 \%$ & $670-710$ \\
No. X & $42 \%$ & $680-810$
\end{tabular}

Hasekouji-Shuhen site. Three skeletons had been cremated or were fragmented. The other eight individuals were well preserved without any evidence of burning. The age, sex, morphological features, and paleopathological conditions were recorded for these eight specimens. Different views of the crania from this site are shown in Figure 2. For recording occlusal surface wear of the dentition, Smith's (1984) system for anterior teeth (incisors, canines, and premolars) and Scott's (1979) system for molars were adopted. Degrees of cranial suture closure were recorded according to the criteria of Meindl and Lovejoy (1985). Morphological changes of the pubic symphyseal face were scored following the scoring system of Todd (1921a, b). Estimation of age-at-death of the subadult remains was based on dental calcification and eruption, following the scale of Ubelaker (1989).

\section{No. 1: sex, male; age, old adult (50-60 years old)}

This skeleton is well preserved with an almost complete skull. The narrow greater sciatic notch and subpubic angle indicate that the sex is male. The tooth crown surfaces are heavily worn (anterior teeth, score 5; molars, score 6). The
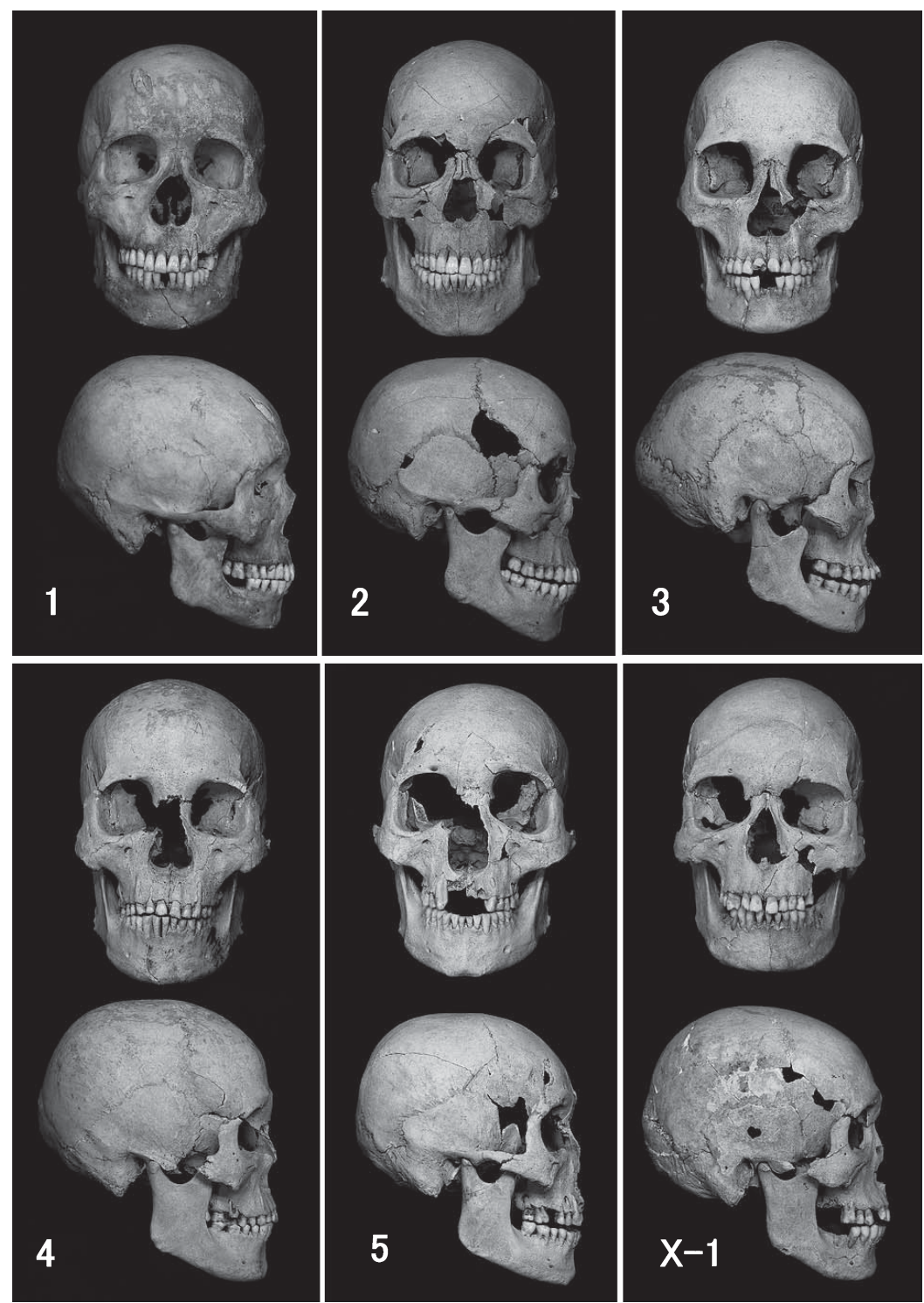

Figure 2. Frontal and lateral views of the skulls from the Hasekouji-Shuhen site. 
sagittal and lambdoidal sutures are completely fused on both the outer and inner surfaces (stage 3, complete obliteration). The pubic symphyseal face exhibits well-defined rims and irregular ossifications (phase 10). Age at death of this individual is estimated to be old adult (50-60 years).

The facial skeleton is characterized by a prominent glabella region, flat superciliary arch, thin nasal bones, flat nasal root, rectangular orbital shape, over-bite occlusion at the incisors, and a high facial height (upper facial height, $71 \mathrm{~mm}$ ). The maxillary central incisors exhibit marked shoveling (depth of lingual fossa, $1.09 \mathrm{~mm}$ ).

This skull shows a deep depression on the outer surface of the frontal bone (Figure 3). The depressed area expands toward the sagittal plane and measures $3 \mathrm{~cm}$ by $1 \mathrm{~cm}$. There is no evidence of healing. The inner surface of the frontal bone projects inwards in this area. This injury might be due to an attack with a sharp implement.

There were no dental caries in this individual.
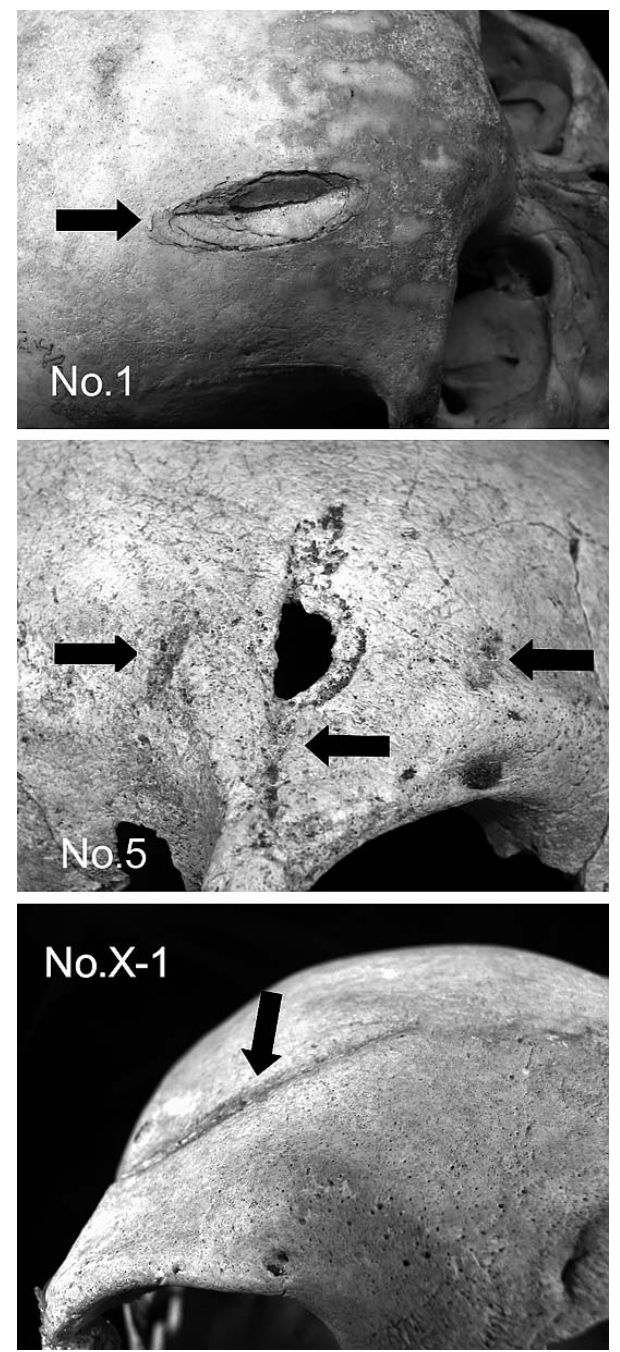

Figure 3. Scars found on the right side of the frontal bones in three individuals from the Hasekouji-Shuhen site.

\section{No. 2: sex, male; age, young adult (20-30 years old)}

This skeleton is almost complete. The sex is male judging from the os coxae. The tooth crown surfaces are slightly worn (anterior teeth, score 2; M1, score 5; M2 and M3, score 3 ). The major cranial sutures (coronal, sagittal, and lambdoidal) are not fused ecto- or endocranially (degree 0). Age at death of this individual is estimated to be young adult (2030 years).

The facial skeleton is very high (upper facial height, $75 \mathrm{~mm}$ ). The orbital shape is round. The glabella region, superciliary arch, and nasal root are flat. Incisor edge-toedge occlusal bite is observed. The maxillary central incisors show marked shoveling (depth of lingual fossa, $1.38 \mathrm{~mm}$ ).

Dental caries were observed in four teeth: the maxillary left first and right second molars, and the right and left mandibular second molars. Of these, the left maxillary first molar exhibit severe carious destruction that has led to the crown of this tooth being entirely lost. In the other molars, caries occur as small pits that have eroded the tooth crown grooves.

\section{No. 3: sex, female; age, middle-aged adult (30-40 years} old)

This skeleton is well preserved. The pelvis indicates that the sex is female. The moderately worn tooth crown surfaces (anterior teeth, score 4; molars, score 6), unfused major sutures of the calvarium (stage 0 ), and the fine-grained pubic symphyseal face (phase 6) indicate that this individual is a middle-aged adult (30-40 years).

The facial skeleton is relatively low (upper facial height, $64 \mathrm{~mm}$ ). The orbital shape is square and the orbits are placed high. The glabella region, superciliary arches, and nasal root are very flat. The incisor occlusal pattern shows an over-bite. The maxillary central incisors are moderately shovel-shaped (depth of lingual fossa, $0.95 \mathrm{~mm}$ ).

Dental caries were observed in the right maxillary central incisor, the mandibular second molars of both sides, and the left mandibular third molar. The mesial half of the superior crown of the right maxillary central incisor is missing, a deep pit was observed on the surface of the worn dentine, obviously not due to attrition. Although some postmortem chipping is visible on the maxillary central incisor, the depth of the lesion suggests caries. The mandibular molars have small eroded pits on the tooth crown grooves and fissures.

\section{No. 4: sex, male; age, middle-aged to old adult (35-60 years old)}

The skull is well preserved except for the cranial base. The pelvic indicators clearly suggest the sex is male. The tooth crown surfaces are heavily worn (anterior teeth, score 5; molars, score 8). The major sutures of the calvarium are partially or completely fused on the outer surfaces (coronal, stage 1; sagittal and lambdoidal, stage 3) and are completely fused on the inner surfaces (stage 3 ). The pubic symphyseal face is fine grained although furrows still remain (phase 6). From these findings, the age at death of this male is estimated to be between middle-aged and old (35-60 years).

The facial skeleton is relatively high (upper facial height, $69 \mathrm{~mm}$ ), the orbital shape is rounded, the glabella region is weakly developed, and the superciliary arches are flat. The 
degree of the shovel-shaped incisors is unclear due to heavy attrition. Incisor occlusion shows over-bite.

Dental caries were found in the left maxillary first molar and the mandibular first molars on both sides. The crown of the left maxillary first molar is completely missing due to severe caries. Alveolar abscess is present at the roots of the right maxillary first molar.

No. 5: sex, male; age, middle-aged adult (30-40 years old)

This skeleton is nearly complete. Based on the os coxae, the sex of this skeleton is male. The age at death is estimated to be middle-aged (30-40 years), from the moderately worn teeth (anterior teeth, score 4; molars, score 5), the mostly fused major cranial sutures on the endocranial surfaces (stage 2), and the somewhat granular appearance of the pubic symphyseal face despite the presence of some ridges and furrows (phase 5).

The skull possesses a high facial skeleton (upper facial height, $71 \mathrm{~mm}$ ), slightly protruding glabella, and rounded orbital margins. Incisor occlusion is not observable due to the missing maxillary incisors.

Dental caries were observed in four maxillary teeth: the left first premolar, the right first and third molars, and the left third molar. The left third molar exhibits erosion at the dental cervical line on the buccal side due to severe caries. The other teeth are eroded on the occlusal crown surfaces.

Three shallow cut marks are observed on the right side of the frontal bone in the temporal fossa region (Figure 3). The outer two cut marks are short in length, less than $1 \mathrm{~cm}$ long, while the middle one is about $4 \mathrm{~cm}$ long.

Other skeletal lesions are observed in this skeleton. Large bony growths form sessible protuberances in the distal metaphyseal areas of the femora, tibiae, and fibulae (Figure 4). The right forearm bones exhibit severe shortening associated with strong radial and ulnar bowing, marked deformations at the radio-ulnar distal joints, and subsequent posterior dislocation of the ulna. According to T. Suzuki (personal communications), these characteristics are most likely due to multiple cartilaginous exostosis rather than enchondromatosis, myositis ossificans, or chondrosacroma. Suzuki will report on further details of this patholoy elsewhere.

No. 6: sex, female; age, middle-aged adult ( $30-50$ years)

This skeleton is only partly preserved. Portions of the cranium and the lower leg bones are preserved. The gracile cranium with small mastoid processes suggests that the sex is female. The tooth crown surfaces are moderately worn (anterior teeth, score 4; molars, score 6). Dental caries are not observed in the teeth present.

\section{No. 7: sex, unknown; age, child (about 5 years)}

This skeleton is relatively well preserved. The deciduous teeth are fully erupted and the first permanent molars are visible in the alveoli. The age at death is estimated to be approximately 5 years. Dental caries is not observed in any of teeth of this child.

No. $X-1$ : sex, male; age, middle-aged adult (40-50 years) The skull is nearly complete, although the preservation of
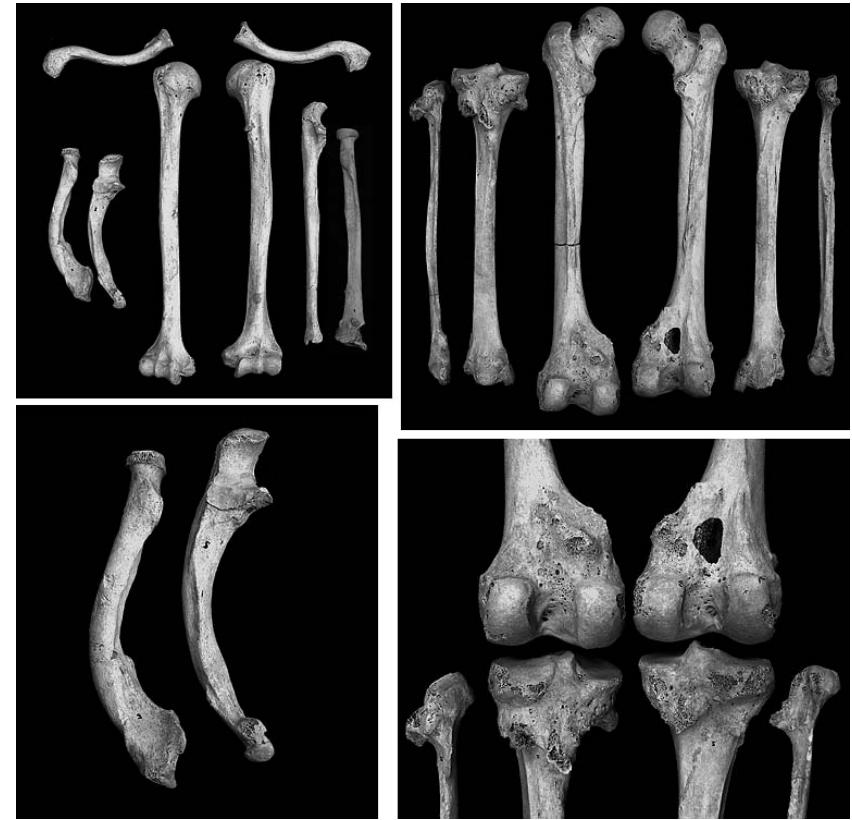

Figure 4. The skeletal lesions in the adult male No. 5 diagnosed as multiple cartilaginous exostosis (upper left, upper limb bones; upper right, lower limb bones; lower left, close up of the right radius and ulna; lower right, close up of lower limbs around knee joint).

the postcranial bones is poor. The pelvis indicates the sex is male. The tooth crown surfaces are heavily worn (anterior teeth, score 5; molars, score 7). Only the coronal suture is completely fused on the inner surface (stage 3 ). The age at death is estimated to be middle-aged ( $40-50$ years).

The cranium exhibits robust features. The glabella region and superciliary arches are prominent. The nasal root is moderately concave. The orbital shape is square. The facial skeleton is high (upper facial height, $71 \mathrm{~mm}$ ). The degree of shoveling of the maxillary incisors is weak (depth of lingual fossa, $0.34 \mathrm{~mm}$ ). Incisor occlusion shows over-bite.

Dental caries were observed on the distal crown surfaces of the left upper first molar and on the cervical line of the mesial side of upper second molar.

This cranium has a wide scar on the right forehead region of the frontal bone (Figure 3). A bony ridge runs obliquely for a length of $5 \mathrm{~cm}$, although no cut marks are present. This injury was obviously ante-mortem because there is clear evidence of the bone healing around the lesion. There is a possibility that the damage was caused by a simple fracture; however, the fracture is not traceable on the inner surface of the frontal bone. We speculate that the damage resulted from an attack with a sword-like weapon.

\section{Cranial Metrics}

Cranial measurements were recorded by one of us (H.M.), following the method of Martin and Saller (1957). The facial flatness measurements were recorded according to the methods outlined in Yamaguchi (1973). The results of the cranial measurements of the Hasekouji-Shuhen series are given in Table 3 . The mean values are presented only in males 
Table 3. Cranial measurements $(\mathrm{mm})$ of the Hasekouji-Shuhen series

\begin{tabular}{|c|c|c|c|c|c|c|c|c|c|}
\hline & Specimen No. & 1 & 2 & 3 & 4 & 5 & $\mathrm{X}-1$ & \multicolumn{2}{|c|}{ Male average } \\
\hline & Sex & Male & Male & Female & Male & Male & Male & Mean & SD \\
\hline 1. & Maximum cranial length & 181 & 187 & 180 & 183 & 176 & 180 & 181.4 & 4.0 \\
\hline 5. & Basion-nasion length & 105 & 104 & 95 & & 97 & & 102.0 & 4.4 \\
\hline 8. & Maximum cranial breadth & 136 & 141 & 124 & 138 & 141 & 141 & 139.4 & 2.3 \\
\hline 9. & Minimum frontal breadth & 92 & 91 & 88 & 87 & 96 & & 91.5 & 3.5 \\
\hline 10. & Maximum frontal breadth & 115 & 118 & 108 & 111 & 116 & & 115.1 & 2.7 \\
\hline 17. & Basion-bregma height & 140 & 145 & 135 & & 136 & & 140.3 & 4.5 \\
\hline 25. & Sagittal arc & 362 & 388 & 358 & 376 & 358 & 378 & 372.4 & 12.3 \\
\hline 26. & Frontal arc & 123 & 130 & 116 & 130 & 125 & & 127.0 & 3.6 \\
\hline 27. & Parietal arc & 131 & 139 & 128 & 125 & 119 & & 128.5 & 8.5 \\
\hline 28. & Occipital arc & 108 & 118 & 114 & 120 & 116 & & 115.5 & 5.3 \\
\hline 40. & Basion-prosthion breadth & 99 & 98 & 89 & & 94 & & 97.0 & 2.6 \\
\hline 43. & Upper facial breadth & 101 & 107 & 102 & 97 & 109 & & 103.5 & 5.5 \\
\hline 45. & Bizygomatic breadth & 136 & 143 & 128 & 133 & 146 & 136 & 138.6 & 5.7 \\
\hline 46. & Bimaxillary breadth & 106 & 106 & 102 & 106 & 107 & & 106.1 & 0.4 \\
\hline 48. & Upper facial height & 71 & 75 & 64 & 69 & 71 & 71 & 71.5 & 2.3 \\
\hline 51. & Orbital breadth & 42 & 41 & 42 & 41 & 44 & 43 & 42.1 & 1.4 \\
\hline 52. & Orbital height & 33 & 34 & 35 & 34 & 39 & 35 & 35.2 & 2.5 \\
\hline 54. & Nasal breadth & 28 & 24 & 27 & 28 & 26 & 25 & 26.2 & 2.0 \\
\hline 55. & Nasal height & 52 & 52 & 50 & 52 & 56 & 55 & 53.2 & 1.7 \\
\hline 66. & Bigonial breadth & 108 & 120 & 94 & 105 & 110 & & 110.6 & 6.7 \\
\hline 68. & Mandibular length & 78 & 84 & 85 & 84 & 82 & & 82.2 & 2.9 \\
\hline 69. & Symphyseal height & 33 & 38 & 30 & 36 & 35 & & 35.6 & 2.0 \\
\hline 70. & Ramus height & 64 & 69 & 67 & 61 & 69 & & 65.9 & 3.9 \\
\hline 71. & Ramus breadth & 38 & 36 & 35 & 39 & 36 & & 37.2 & 1.7 \\
\hline $8: 1$ & Cranial index & 75.1 & 75.4 & 68.9 & 75.4 & 80.1 & & 76.5 & 2.4 \\
\hline $17: 1$ & Length-height index & 77.3 & 77.5 & 75.0 & & 77.3 & & 77.4 & 0.1 \\
\hline $17: 8$ & Breadth-height index & 102.9 & 102.8 & 108.9 & & 96.5 & & 100.7 & 3.7 \\
\hline $48: 45$. & Upper facial index & 52.2 & 52.7 & 50.1 & 52.2 & 48.7 & & 51.5 & 1.8 \\
\hline $48: 46$. & Upper facial index (Virchow) & 66.9 & 71.1 & 62.8 & 65.4 & 66.7 & & 67.5 & 2.5 \\
\hline $52: 51$ & Orbital index & 79.6 & 83.4 & 83.2 & 83.6 & 89.6 & & 84.1 & 4.1 \\
\hline $54: 55$ & Nasal index & 53.7 & 45.4 & 54.2 & 54.2 & 47.3 & & 50.1 & 4.4 \\
\hline & Frontal chord & 94.0 & 96.8 & 94.7 & 92.6 & 101.5 & 102.0 & 97.4 & 4.0 \\
\hline & Frontal subtense & 14.5 & 15.8 & 9.4 & 13.6 & 17.2 & 17.0 & 15.6 & 2.9 \\
\hline & Frontal index & 15.5 & 16.3 & 10.0 & 14.7 & 16.9 & 16.6 & 16.0 & 2.6 \\
\hline & Simotic chord & 6.5 & 6.0 & 5.9 & & & & 6.2 & 0.3 \\
\hline & Simotic subtense & 2.5 & 1.7 & 1.1 & & & & 2.1 & 0.7 \\
\hline & Simotic index & 38.4 & 28.9 & 18.6 & & & & 33.7 & 6.7 \\
\hline & Zygomaxillary chord & 103.9 & 107.9 & 100.9 & 102.0 & 103.8 & 104.5 & 104.4 & 2.4 \\
\hline & Zygomaxillary subtense & 19.9 & 19.5 & 18.1 & 20.3 & 21.3 & 24.5 & 21.1 & 2.2 \\
\hline & Zygomaxillary index & 19.1 & 18.1 & 17.9 & 19.9 & 20.5 & 23.4 & 20.2 & 2.0 \\
\hline
\end{tabular}

because of the small number of female specimens.

A comparison of the standardized means of the ten cranial linear variables and nine indices of the Hasekouji-Shuhen males is provided in Figure 5, together with the standardized means of the medieval Kamakura period Zaimokuza series (Suzuki, 1956) and the protohistoric Kofun series from eastern Japan (Yamaguchi, 1987). The means and standard deviations of the modern Japanese series of Morita (1950) were used in standardizing the means of each skeletal series; the standardized means are the relative deviations from the modern Japanese means. The overall pattern of the standardized means of the Hasekouji-Shuhen series resembles that of the Kofun sample of eastern Japan, while that of the Kamakura sample differs from the Hasekouji-Shuhen pattern. In the measurement items that exhibit a difference of the standardized means of greater than 0.5 units, the Hasekouji-Shuhen means are larger than those of the Kofun and Kamakura series in the cranial and facial height measurements, as represented by basion-bregma height, upper facial height, orbital height, and nasal height. The facial skeleton of the Hasekouji-Shuhen sample is much higher than that of the Kamakura and Kofun samples, as indicated also by the upper facial index. The indices of facial flatness of the three protohistoric/historic series are very similar; all three series are characterized by flatter faces than the modern Japanese.

The standardized means of the Yayoi (northern Kyushu and Yamaguchi prefecture) and Jomon cranial series are also provided in Figure 5. The cranial measurements of the Yayoi series were taken from Nakahashi et al. (1989) and the facial flatness measurements from Ishida (1992). The cranial measurements of the Jomon series were recorded by Suzuki (1969), and facial flatness measurements of the same series were recorded by Yamaguchi (1980). In this comparison, the Hasekouji-Shuhen sample resembles the Yayoi rather than the Kofun series (Figure 5). The close morphological affinity between the Hasekouji-Shuhen and Yayoi series is due to the larger orbital, nasal, and upper facial heights of the Yayoi sample, which are not seen in the Kofun sample. On the 

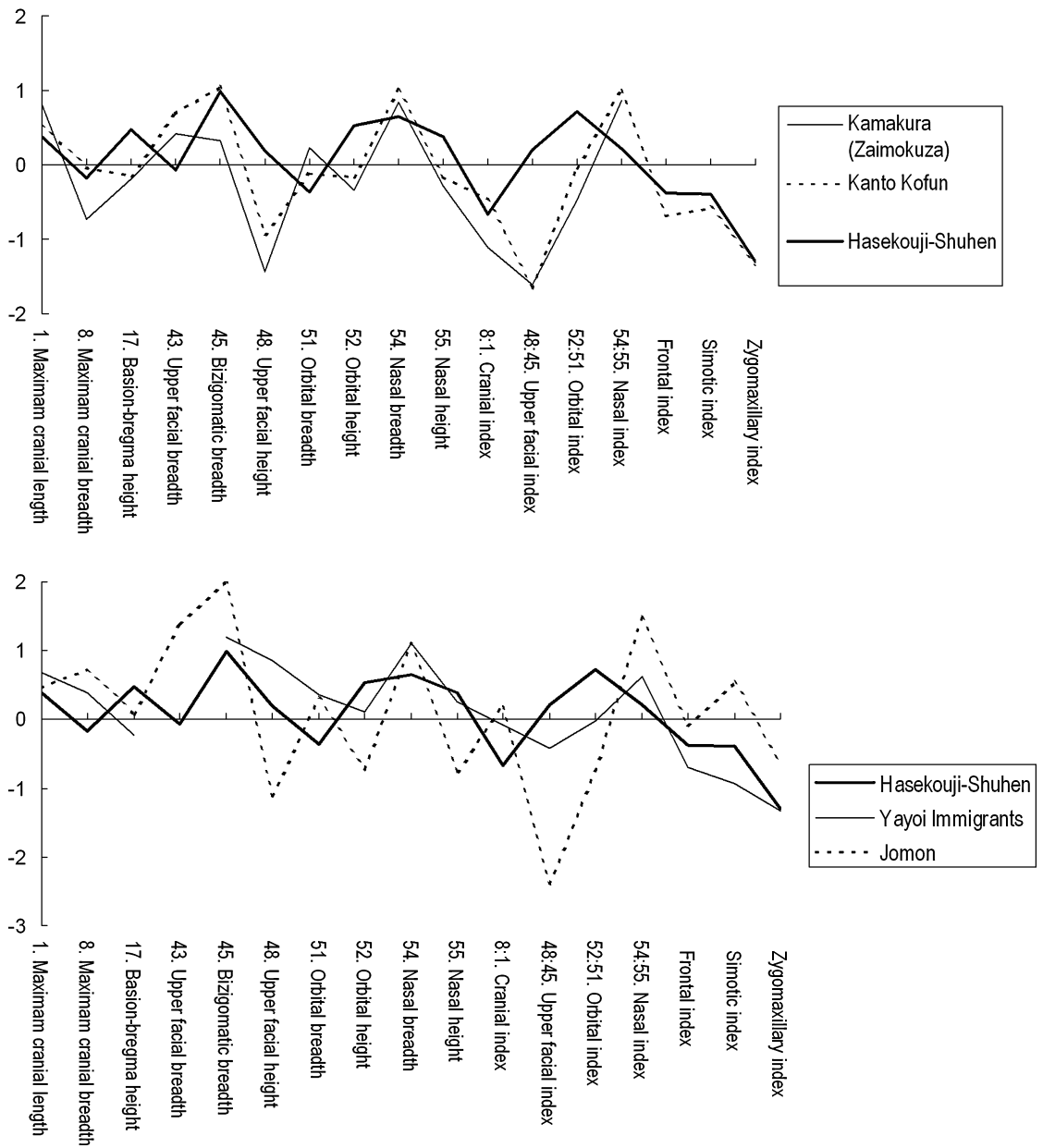

Figure 5. Standardized means of 10 cranial measurements and 3 facial flatness indices of the Hasekouji-Shuhen and the comparative series. The modern Kanto Japanese male means and standard deviations were used in the standardization of sample means.

other hand, the Jomon series exhibits a pattern that contrasts with that of the Hasekouji-Shuhen sample, especially in the low upper facial index.

In order to further examine the cranial affinities of the Hasekouji-Shuhen series, Penrose's shape distance (Penrose, 1954) and a distance measure $(1-r)$ based on the $Q$-mode correlation coefficient were computed using eight cranial measurements (Martin's numbers 1, 8, 45, 48, 51, 52, 54, and 55) (Table 4). The results of either of the two methods place the Hasekouji-Shuhen males closest to the Yayoi, and well separated from the Jomon.

\section{Dental Metrics}

The mesiodistal and buccolingual tooth crown diameters of the permanent dentition of the Hasekouji-Shuhen series were recorded by one of us (H.M.), following the method of Fujita (1949). The measurements were taken on teeth from the right side, except when the right side tooth was missing or heavily worn, in which case the left side was measured. The results are given in Table 5. The means values are given only in males, because there was only one female specimen.

Using the means and standard deviations of modern Japa-
Table 4. Distance from the Hasekouji-Shuhen males to six comparative population samples based on 8 cranial and 28 tooth crown measurements

\begin{tabular}{lcccc}
\hline & \multicolumn{2}{c}{ Distance by skull } & \multicolumn{2}{c}{ Distance by teeth } \\
\cline { 2 - 5 } & $C q^{2}$ & $1-r$ & $C q^{2}$ & $1-r$ \\
\hline Medieval Kanto Kamakura & 0.583 & 0.131 & 0.291 & 0.756 \\
Kanto Kofun & 0.284 & 0.047 & 0.507 & 1.159 \\
Yayoi immigrants & 0.167 & 0.017 & 0.371 & 0.743 \\
Kanto Jomon & 0.976 & 0.155 & 0.347 & 1.144 \\
Modern Kanto Japanese & 0.276 & 0.053 & 0.374 & 0.856 \\
\hline
\end{tabular}

$C q^{2}$, Penrose's shape distance; $1-r$, distance derived from the $Q$ mode correlation coefficient.

nese males (Matsumura, 1989), the standardized means of the 28 tooth crown diameters of the Hasekouji-Shuhen male sample were calculated (Figure 6). We also included the following male series in this comparison: Kanto Jomon, Yayoi, a Kofun sample from eastern Japan, and medieval Kamakura from the Kanto region (Matsumura, 1989, 1990, 1994). As shown in the upper portion of Figure 6, the HasekoujiShuhen pattern of the standardized means is very different 
Table 5. Dental crown measurements (mm) of the Hasekouji-Shuhen series

\begin{tabular}{|c|c|c|c|c|c|c|c|c|}
\hline No. & 1 & 2 & 3 & 4 & 5 & $X-1$ & \multicolumn{2}{|c|}{ Male average } \\
\hline Sex & Male & Male & Female & Male & Male & Male & Mean & SD \\
\hline \multicolumn{9}{|c|}{ Mesiodistal diameters } \\
\hline UI1 & 8.41 & 9.18 & 8.77 & & & 8.69 & 8.76 & 0.39 \\
\hline UI2 & 7.37 & 8.25 & 7.05 & & & 6.07 & 7.23 & 1.10 \\
\hline UC & 8.00 & 8.77 & 8.00 & & 8.11 & 7.53 & 8.10 & 0.51 \\
\hline UP1 & 6.74 & 7.53 & 7.47 & & 7.31 & 7.18 & 7.19 & 0.33 \\
\hline UP2 & 6.32 & 7.09 & 7.12 & & 6.84 & 6.25 & 6.63 & 0.41 \\
\hline UM1 & 10.35 & 11.07 & 10.58 & & & & 10.71 & 0.51 \\
\hline UM2 & 9.86 & 10.02 & 10.13 & & 10.73 & & 10.20 & 0.46 \\
\hline LI1 & 5.05 & 5.60 & 5.27 & & & 5.10 & 5.25 & 0.51 \\
\hline LI2 & 5.82 & 6.74 & 6.16 & & 5.66 & 5.98 & 6.05 & 0.48 \\
\hline $\mathrm{LC}$ & 7.01 & 7.40 & 7.49 & & 6.82 & 6.86 & 7.02 & 0.26 \\
\hline LP1 & 6.34 & 7.72 & 7.09 & & 6.51 & 7.42 & 7.00 & 0.68 \\
\hline LP2 & 6.95 & 7.60 & 7.62 & & 6.13 & & 6.89 & 0.74 \\
\hline LM1 & 11.03 & 11.86 & 11.85 & & 11.05 & & 11.31 & 0.47 \\
\hline LM2 & 11.05 & 11.67 & 11.47 & & 10.85 & & 11.19 & 0.43 \\
\hline \multicolumn{9}{|c|}{ Buccolingual diameters } \\
\hline UI1 & 7.76 & 7.51 & 7.83 & 7.74 & & 7.72 & 7.68 & 0.12 \\
\hline UI2 & 7.10 & 7.12 & 7.67 & 6.55 & & 6.30 & 6.77 & 0.41 \\
\hline UC & 8.73 & 9.15 & 8.13 & 8.68 & 8.87 & 8.53 & 8.79 & 0.23 \\
\hline UP1 & 9.33 & 10.15 & 10.10 & 9.51 & 10.10 & 9.64 & 9.75 & 0.36 \\
\hline UP2 & 9.35 & 10.09 & 10.33 & & 9.35 & & 9.60 & 0.43 \\
\hline UM1 & 11.71 & 12.63 & 12.85 & & 11.45 & 11.93 & 11.93 & 0.51 \\
\hline UM2 & 12.27 & 12.43 & 12.26 & & 12.13 & & 12.28 & 0.15 \\
\hline LI1 & 6.44 & 5.90 & 6.15 & 6.10 & 6.34 & 6.34 & 6.22 & 0.22 \\
\hline LI2 & 6.29 & 6.37 & 6.65 & 6.84 & 6.38 & 6.89 & 6.55 & 0.29 \\
\hline $\mathrm{LC}$ & 8.88 & 7.96 & 8.19 & 8.68 & 8.16 & 8.00 & 8.34 & 0.42 \\
\hline LP1 & 8.30 & 8.22 & 8.84 & 8.21 & 7.64 & 8.35 & 8.14 & 0.29 \\
\hline LP2 & 8.69 & 8.07 & 9.27 & & 8.93 & & 8.56 & 0.44 \\
\hline LM1 & 11.27 & 11.35 & 11.14 & & 10.47 & & 11.03 & 0.49 \\
\hline LM2 & 10.69 & 11.04 & 10.72 & & 10.21 & & 10.65 & 0.42 \\
\hline
\end{tabular}

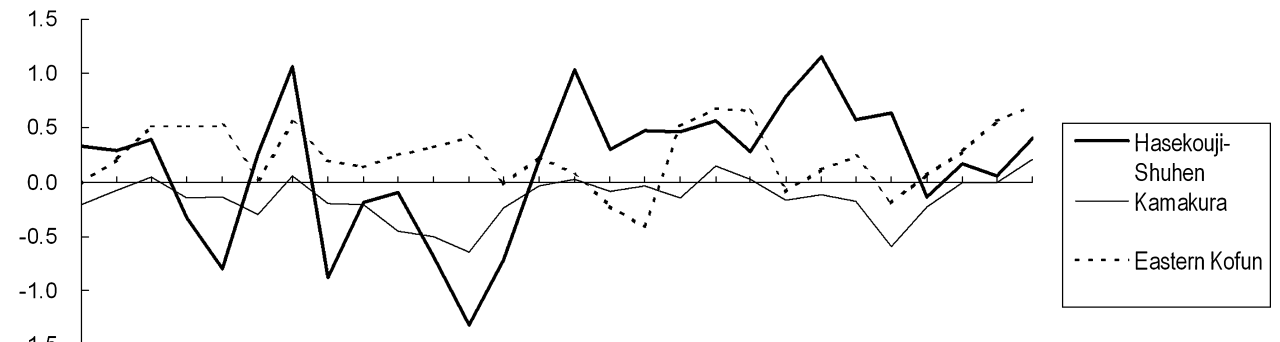

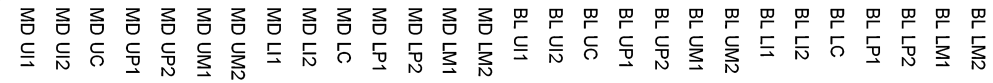

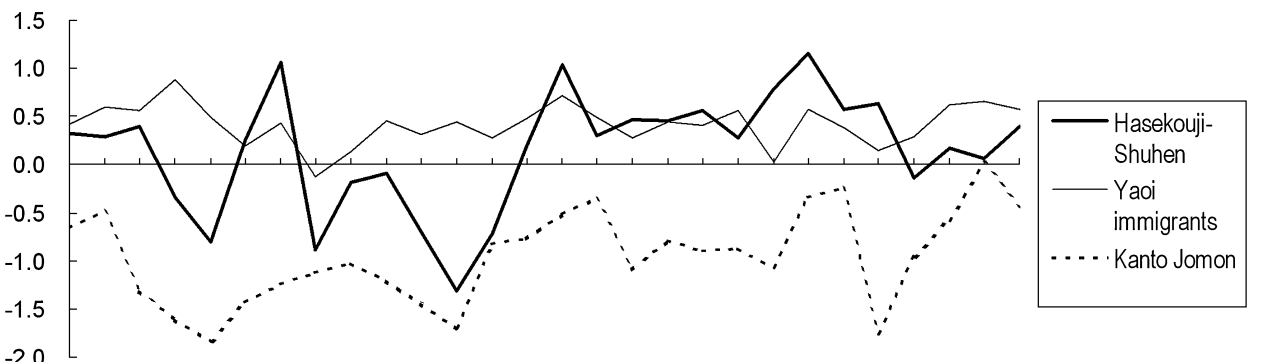

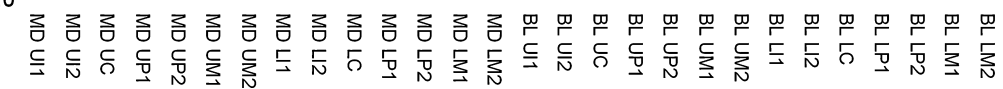

Figure 6. Standardized means of 28 dental tooth crown measurements of the Hasekouji-Shuhen and the comparative series. The modern Kanto Japanese male means and standard deviations were used in the standardization of sample means. 
from that of the Kamakura and Kofun series. Compared with the Kanto Jomon and the Yayoi immigrant series (Figure 6, bottom), the Hasekouji-Shuhen series shows a close affinity to the Yayoi immigrant series only in the buccolingual diameters.

Penrose's shape distance (Penrose, 1954) and a distance measure $(1-r)$ based on the $Q$-mode correlation coefficient were computed between the Hasekouji-Shuhen males and the comparative series, using the 28 tooth crown diameters presented in Table 4. Both distances indicate that the Hasekouji-Shuhen and medieval Kamakura samples are morphologically close. Examination of the $Q$-mode correlation coefficients indicates an affinity between these and the Yayoi series as well.

\section{Limb Bone Metrics}

The limb bone measurements of the Hasekouji-Shuhen series are given in Table 6. Because of anomalies in the right forearm and leg bones noted for Burial No. 5, the following comparisons were made using data only from the left side.

Some metric indices and estimated stature based on the limb bone measurements were compared with data available for the following comparative seris: Yayoi from western Japan (Nakahashi et al., 1989), a Kofun sample from eastern Japan (Yamaguchi, 1987), and a combined Jomon sample from all regions of Japan (Yamaguchi, 1989). This comparison was made only with males, because there was only a single female specimen from Hasekouji-Shuhen. The

Table 6. Limb bone measurements ( $\mathrm{mm})$ of the Hasekouji-Shuhen series

\begin{tabular}{|c|c|c|c|c|c|c|c|c|c|c|}
\hline Specimen No. & 1 & 2 & 3 & 4 & 5 & 5 & 6 & $\mathrm{X}-1$ & \multicolumn{2}{|c|}{ Male average $^{1}$} \\
\hline Sex & Male & Male & Female & Male & \multicolumn{2}{|c|}{ Male } & Female & Male & Mean & $\mathrm{SD}$ \\
\hline Humerus & Left & Left & Left & Left & Left & Right & & Left & & \\
\hline 1 Maximum length & 289 & & 300 & 300 & 310 & 314 & & & 299.7 & 10.5 \\
\hline 4 Biepicondylar width & 64 & & 56 & 57 & 60 & 57 & & & 60.7 & 3.4 \\
\hline 5 Maximum midshaft diameter & 22 & 24 & 20 & 20 & 21 & 20 & & 24 & 22.1 & 2.0 \\
\hline 6 Minimum midshaft diameter & 20 & 21 & 15 & 16 & 17 & 16 & & 16 & 18.0 & 2.1 \\
\hline 9 Transverse head diameter & 46 & & 39 & 41 & 44 & 42 & & & 43.2 & 2.5 \\
\hline 10 Sagittal diameter of the head & 48 & & 40 & 39 & 47 & 45 & & & 44.5 & 5.1 \\
\hline $6: 5$ Index of cross-section of midshaft & 90 & 84 & 75 & 83 & 81 & 80 & & 69 & 81.5 & 7.8 \\
\hline Radius & Left & Left & Left & Left & Left & Right & & Right & & \\
\hline 1 Maximum length & 217 & 235 & 235 & 240 & 218 & 154 & & & 227.5 & 11.7 \\
\hline 4 Transverse shaft diameter & 15 & 16 & 13 & 13 & 15 & 15 & & 19 & 15.6 & 2.1 \\
\hline 5 Sagittal shaft diameter & 13 & 13 & 11 & 12 & 12 & 13 & & 12 & 12.3 & 0.3 \\
\hline $5: 4$ Index of cross-section of midshaft & 82 & 76 & 86 & 92 & 83 & 87 & & 67 & 79.9 & 9.3 \\
\hline Ulna & Left & Right & Left & Right & Left & Right & & Left & & \\
\hline 1 Maximum length & 239 & 260 & 250 & 260 & 240 & 152 & & & 249.8 & 11.8 \\
\hline 11 Dorsovolar shaft diameter & 18 & 15 & 13 & 13 & 16 & 15 & & 13 & 14.9 & 1.8 \\
\hline 12 Transverse shaft diameter & 14 & 17 & 12 & 16 & 16 & 13 & & 16 & 15.9 & 0.9 \\
\hline $11: 12$ Index of cross-section of midshaft & 122 & 88 & 106 & 80 & 99 & 115 & & 81 & 94.0 & 17.2 \\
\hline Femur & Left & Left & Left & Left & Left & Right & & Right & & \\
\hline 1 Maximum length & 412 & & 422 & 422 & 415 & 397 & & 423 & 418.0 & 5.4 \\
\hline 6 Sagittal midshaft diameter & 29 & 30 & 29 & 26 & 30 & 31 & & 28 & 28.6 & 1.5 \\
\hline 7 Transverse midshaft diameter & 27 & 29 & 26 & 27 & 28 & 26 & & 30 & 28.3 & 1.0 \\
\hline 18 Medio-head diameter & 49 & & 43 & 43 & 48 & 48 & & & 46.8 & 3.7 \\
\hline 19 Transverse diameter of the head & 48 & & 43 & 43 & 48 & 47 & & & 46.4 & 3.0 \\
\hline $6: 7$ Index of cross-section of midshaft & 107 & 102 & 110 & 96 & 106 & 119 & & 94 & 101.0 & 5.7 \\
\hline Tibia & Left & Right & Left & Left & Left & Right & Right & & & \\
\hline 1a Maximum length & 333 & & & & 330 & 344 & 312 & & 331.5 & 2.1 \\
\hline 8 Maximum midshaft diameter & 30 & 34 & 28 & 29 & 29 & 28 & 24 & & 30.4 & 2.2 \\
\hline 9 Transverse midshaft diameter & 24 & 23 & 19 & 22 & 22 & 22 & 21 & & 22.8 & 1.1 \\
\hline $9: 8$ Index of cross-section of midshaft & 80 & 68 & 68 & 75 & 78 & 79 & 87 & & 75.1 & 5.3 \\
\hline Fibula & Left & Left & Left & Left & Left & Right & Left & & & \\
\hline 1 Maximum length & 324 & & & & 324 & 322 & & & 324.0 & 0.0 \\
\hline 2 Maximum midshaft diameter & 16 & 17 & 12 & 13 & 17 & 18 & 12 & & 16.0 & 1.7 \\
\hline 3 Minimum midshaft diameter & 10 & 13 & 10 & 12 & 11 & 12 & 9 & & 11.6 & 1.5 \\
\hline $3: 2$ Index of cross-section of midshaft & 61 & 78 & 83 & 90 & 65 & 67 & 76 & & 73.5 & 13.3 \\
\hline Radiohumeral index & 75.1 & & 78.3 & 80.0 & 70.3 & 49.0 & & & 75.1 & 4.8 \\
\hline Tibiofemoral index & 80.8 & & & & 79.5 & 86.6 & & & 80.2 & 0.9 \\
\hline Estimated stature & 162.0 & 160.0 & 156.0 & 164.0 & 157.4 & 153.0 & & & 160.9 & 2.8 \\
\hline
\end{tabular}

\footnotetext{
${ }^{1}$ Data from the right side of individual No. 5 were not included in the basic statistics because of skeletal abnormalities.
} 
Hasekouji-Shuhen pilastric index of the femur (index 6:7, mean 101.0) is most similar to that of the eastern Japan Kofun (mean 102.2); the Hasekouji-Shuhen mean is smaller than both the Yayoi (106.4) and Jomon (110.6) means. The Hasekouji-Shuhen tibial mid-shaft index (index 9:8, mean 75.1) is closer to the Yayoi (72.2) and Kofun (73.8) means than to the Jomon mean (69.8). The Hasekouji-Shuhen radiohumeral index (mean 75.1) is smaller than that of the Yayoi (mean 78.2) and much smaller than in the Jomon (mean 80.5). The Hasekouji-Shuhen tibiofemoral index (mean 80.2) is closest to the Yayoi (81.3), and less than the means of the Kofun (82.1) and Jomon (83.2) series.

The estimated statures of the Hasekouji-Shuhen individuals shown in Table 6 are mostly based on the maximum length of the femur, using Fujii's formulae (Fujii, 1960). The stature of Burial No. 2, from which the femora were missing, was calculated using the maximum length of the radius. The mean male stature of the Hasekouji-Shuhen series is $160.9 \mathrm{~cm}$, which is intermediate between that of the Yayoi $(162.6 \mathrm{~cm})$ and the Kofun series $(160.4 \mathrm{~cm})$, but higher than that of the Kamakura $(159.0 \mathrm{~cm})$ and Jomon $(159.1 \mathrm{~cm})$, according to the estimates of Hiramoto (1972).

\section{Discussion and Conclusions}

The results of the AMS dating, 670-970 calAD, reveal that the human remains from the Hasekouji-Shuhen site do not belong to either the Yayoi or the protohistoric Kofun periods. They most likely date to the early historic Asuka (500-710 AD), the subsequent Nara (710-794 AD), and early Heian (794-1192 AD) periods. Although the skeletons are not of Yayoi age as initially thought, these specimens are important because of the scarcity of ancient human skeletal remains from the early historic Asuka-Nara-Heian periods in Japan.

In debating the population history of Japan, one crucial topic of interest is the nature and degree of influx of immigrant people from the Asian continent, from the Yayoi to Kofun and early historic periods (Hanihara, 1987, 1991). Thus far, well-dated Yayoi skeletons have been found only from a few sites in eastern Japan (Yoneda et al., 2005). In the Kanto region, human skeletal remains associated with the Yayoi period were discovered at the Awajinsha site in Chiba prefecture (Suzuki, 1969), the Bishamon and Ourayama sites in Kanagawa prefecture (Suzuki, 1969, 1998), and the Iwatsubo site in Gunma prefecture (Kaifu, 1992) - all these remains are generally poorly preserved. Of these five Yayoi sites, Matsumura (2001) found charcteristics in the dental measurements of the Bishamon specimens that were suggestive of immigrant affinities. By contrast, the sites from the Kofun period have yielded a large number of human skeletal remains that allow the study of the impact of the new immigrants. Several studies have demonstrated that the Kofun remains of the Kanto region retain cranial metric features of the Jomon to a certain extent, although genetic admixture of the immigrants is considered to have been large even in eastern Japan (Morisawa, 1976; Hanihara, 1987; Mizoguchi; 1988; Matsumura, 2001). Given the early historic date of the skeletons from the Hasekouji-Shuhen site, the degree of immigrant genetic influence in this series, as expressed in their skeletal and dental morphology, is worth mentioning.

In general, the skeletons from the Hasekouji-Shuhen site are characterized by large upper facial heights, high orbital openings, flat nasal roots, strongly developed shovel-shaped maxillary incisors, and relatively tall stature. These features are commonly seen so far in the Yayoi skeletons of western Japan. The results of the distance analysis of the present study, based on cranial measurements, confirm the close similarity of the Hasekouji-Shuhen sample to the Yayoi rather than to the Kofun people of eastern Japan. The comparison of limb bone proportions further demonstrates the similarities between the Hasekouji-Shuhen and the Yayoi series, although the affinity with the Yayoi series is not clearly indicated in the dental measurements. These findings suggest a strong influence from the Yayoi or subsequent immigrants on the Hasekouji-Shuhen people of the early historic period.

As is well known, the people of medieval Kamakura (1314th centuries), represented by the sample from the Zaimokuza site, which is located close to the HasekoujiShuhen site, possess unique cranial features such as a dolichocranic cranium (male average cranial index: 74.2) and marked alveolar prognathism (Suzuki, 1956, 1969). The question arises as to whether they had acquired such specific characters during the medieval period or before. Alveolar prognathism is not found in any of the Hasekouji-Shuhen specimens, though most of them possess relatively long cranial vaults (four of five individuals have cranial index values of about 75 or less, see Table 3 ). The cranial index values of the Hasekouji-Shuhen specimens are higher than in the Kofun sample from eastern Japan (Yamaguchi, 1987) (mean values: males, 78.7; females, 78.8), suggesting that cranial shape of the early historic Hasekouji-Shuhen people had already acquired the tendency toward a dolichocranic cranial shape.

Evidence of trauma was observed in three male skulls. It is of interest that all the injuries are on the right side of the frontal bone, suggesting right-handed fighting with a shield of some sort used with the left hand. Skeletal abnormalities were found in one adult male, whose right forearm bones was shortened and strongly curved, and whose lower limbs possessed a large bony growth forming sessible protuberances. Further paleopathological research is required to identify the cause of these bony lesions.

\section{Acknowledgments}

We wish to thank to Dr Takao Suzuki, Department of Epidemiology and Health Promotion, Tokyo Metropolitan Institute of Gerontology, and Dr Mark J. Hudson, Institute of History and Anthropology, University of Tsukuba, for their help in preparing this paper.

\section{References}

Anezaki T. and Shudai H. (2001) The skeletal remains of late Yayoi to early Kofun period excavated from the Haseko-uji Shu-hen site, Kamakura City, Japan. Anthropological Science, 109: 78 . 
Bronk Ramsey C. (1995) Radiocarbon calibration and analysis of stratigraphy: the OxCal program. Radiocarbon, 37: 425-430.

Bronk Ramsey C. (2001) Development of the radiocarbon calibration program. Radiocarbon, 43: 355-363.

DeNiro M.J. (1985) Postmortem preservation and alteration of in vivo bone-collagen isotope ratios in relation to paleodietary reconstruction. Nature, 317: 806-809.

Dodo Y. and Ishida H. (1990) Population history of Japan as viewed from cranial nonmetric variation. Journal of the Anthropological Society of Nippon, 98: 269-287.

Fujii A. (1960) On the relation of long bone lengths of limbs to stature. Bulletin of School of Physical Education, Juntendo University, Volume 3, pp. 49-61 (in Japanese).

Fujita T. (1949) On the standard for measurement of teeth. The Journal of the Anthropological Society of Nippon, 61: 27-32 (in Japanese).

Hanihara K. (1987) Estimation of the number of early migrants to Japan: a simulative study. Journal of the Anthropological Society of Nippon, 95: 391-403.

Hanihara K. (1991) Dual structure model for the population history of the Japanese. Japan Review, 2: 1-33.

Hideshima S., Matsumoto E., Abe O., and Kitagawa H. (2001) Northwest Pacific marine reservoir correction estimated from annually banded coral from Ishigaki Island, southern Japan. Radiocarbon, 43: 473-476.

Hiramoto K. (1972) Secular change of estimated stature of Japanese in Kanto district from the prehistoric age to the present day. Journal of the Anthropological Society of Nippon, 80: 221-236 (in Japanese).

Hirata K., Oku C., Hoshino K., Tomo S., and Takahashi S. (2002) On human skeletal remains from Yuigahama-minami site. In: Yuigahama-minami Iseki Hakkutsu Chosa Dan (ed.), Yuigahama-minami site (Yuigahama-minami Iseki), Volume 2: Analysis 1. Yuigahama-minami Iseki Hakkutsu Chosa Dan, Kamakura, pp. 1-240 (in Japanese).

Hirata H., Nagaoka T., and Hoshino K. (2004) Analysis of injuries by swords in medieval Japanese skeletons from Yuigahama, Kamakura. Anthropological Science (Japanese Series), 112: 19-26.

Ishida H. (1992) Flatness of facial skeletons in Siberian and other circum-Pacific populations. Zeitschrift für Morphologie und Anthropologie, 79: 53-67.

Kaifu Y. (1992) Human skeletal remains of the Yayoi period from the Iwatsubo Cave Site in Gunma Prefecture, Kanto district. Journal of the Anthropological Society of Nippon, 100: 449483.

Kanaseki T., Nagai M., and Sano H. (1960) Craniological studies of the Yayoi-period ancients excavated at the Doigahama site, Yamaguchi prefecture. Quarterly Journal of Anthropology, 7(Supplement): 1-36 (in Japanese).

Martin R. and Saller K. (1957) Lehrbuch der Anthropologie. Band 1. Gustav Fischer Verlag, Stuttgart.

Matsumura H. (1989) Geographical variation of dental measurements in the Jomon population. Journal of the Anthropological Society of Nippon, 97: 493-512.

Matsumura H. (1990) Geographical variation of dental characteristics in the Japanese of the Protohistoric Kofun period. Journal of the Anthropological Society of Nippon, 98: 439-449.

Matsumura H. (1994). A microevolutional history of Japanese people from dental characteristics perspective. Anthropological Science, 102: 93-118.

Matsumura H. (2001) Differentials of Yayoi immigration to Japan as derived from dental metrics. Homo, 52: 135-156.

Meindl R.S. and Lovejoy C.O. (1985) Ectocranial suture closure: a revised method for the determination of skeletal age at death based on the lateral-anterior sutures. American Journal of Physical Anthropology, 68: 57-66.

Mizoguchi Y. (1988) Affinities of the protohistoric Kofun people of Japan with pre- and proto-historic Asian populations. Jour- nal of the Anthropological Society of Nippon, 96: 71-109.

Morisawa S. (1976) Regional differences in measurements of the human skulls excavated from the Kofun. Niigata Igakkai Zasshi, 90: 32-47 (in Japanese).

Morita S. (1950) Anthropological study of crania: Kanto region population. Report of Department of Anatomy, Jikei University School of Medicine, Volume 3, pp. 1-59 (in Japanese).

Nakahashi T. (1993) Temporal craniometric changes from the Jomon to the modern period in western Japan. American Journal of Physical Anthropology, 90: 409-425.

Nakahashi T., Nagai M., Matsushita T., Naito Y., Hojou T., and Tsurumoto T. (1989) Yayoi people (Yayoi-jin). In: Nagai M., Nasu T., Kanaseki H., and Sahara M. (eds.), Studies on the Yayoi Culture (Yayoi-Bunka no Kenkyu), Volume 1. Yuzankaku shuppan, Tokyo, pp. 23-51 (in Japanese).

Penrose L.S. (1954) Distance, size and shape. Annals of Eugenics, 18: $337-343$.

Scott E.C. (1979) Dental wear scoring technique. American Journal of Physical Anthropology, 51: 213-218.

Shudai H., Ohata A., and Shudai T. (2002) Hasekouji-Shuhen site (No. 236). Bulletin of the Togoku Historical and Archeological Research Center (Rekishikoukogaku Kenkusho Chousa Kenkyu Houkoku), Kamakura, Volume 31 (in Japanese).

Smith B.H. (1984) Patterns of molar wear in hunter gatherers and agriculturalists. American Journal of Physical Anthropology, 63: 39-56.

Stuiver M. and Pollach H.A. (1977) Discussion-reporting 14C data. Radiocarbon, 19: 353-363.

Stuiver M. and Reimer P.J. (1993) Extended 14C data base and revised CALIB 3.0 14C age calibration program. Radiocarbon, 35: 215-230.

Stuiver M., Pearson G.W., and Braziunas T. (1986) Radiocarbon age calibration of marine samples back to $9000 \mathrm{cal}$. yr BP. Radiocarbon, 28: 980-1021.

Stuiver M., Reimer P.J., Bard E., Beck J.W., Burr G.S., Hughen K.A., Kromer B., McCormac F.G., Plicht J., and Spurk M. (1998) INTCAL 98 radiocarbon age calibration 24,000 0 cal. BP. Radiocarbon, 40: 1041-1083.

Suzuki H. (1956) Craniofacial skeletons. In: The Anthropological Society of Nippon (ed.), Medieval Japanese Skeletons from the Burial Site at Zaimokuza, Kamakura City. Iwanami Shoten, Tokyo, pp. 45-148, 155-168 (in Japanese).

Suzuki H. (1969) Microevolutional changes in the Japanese population from the prehistoric age to the present-day. Journal of the Faculty of Science, the University of Tokyo, Section 5, Anthropology, Volume 3, 279-309.

Suzuki H. (1998) A History of Japan as Viewed from Skeletal Remains (Honega Kataru Nihonshi). Gakusei-sha, Tokyo (in Japanese).

Todd T.W. (1921a) Age changes in the pubic bone, I: the male white pubis. American Journal of Physical Anthropology, 3: 285-334.

Todd T.W. (1921b) Age changes in the pubic bone, III: The pubis of the female white-negro hybrid. American Journal of Physical Anthropology, 4: 1-70.

Ubelaker D.H. (1989) The estimation age at death from immature human bone. In: İşcan M.Y. (ed.), Age Markers in the Human Skeleton. Charles C. Thomas, Springfield, Illinois, pp. 55-70.

Yamaguchi B. (1973) Facial flatness measurements of the Ainu and Japanese crania. Bulletin of the National Science Museum, Tokyo, 16: 161-171.

Yamaguchi B. (1980) A study on the facial flatness of the Jomon crania. Bulletin of the National Science Museum Tokyo, Series D, 6: 21-28.

Yamaguchi B. (1985) The incidence of minor non-metric cranial variants in the Protohistoric human remains from eastern Japan. Bulletin of the National Science Museum, Tokyo, Series D, 11: 13-24.

Yamaguchi B. (1987) Metric study of the crania from protohistoric 
sites in eastern Japan. Bulletin of the National Science Museum Tokyo, Series D, 13: 1-9.

Yamaguchi B. (1989) Limb segment proportions in human skeletal remains of the Jomon Period. Bulletin of the National Science Museum Tokyo, Series D, 15: 41-48.

Yoneda M., Tanaka A., Shibata Y., Morita M., Uzawa K., Hirota M., and Uchida M. (2002) Radiocarbon marine reservoir effect in human remains from the Kitakogane site, Hokkaido, Japan. Journal of Archaeological Science, 29: 529-536.

Yoneda M., Shibata Y., Tanaka A., Uehiro T., Morita M., Uchida

\section{Erratum:}

Page 208, right column, line 31 .

Now reads:

"...the Hasekouji-Shuhen specimens are higher than in the..."

Should read:

"...the Hasekouji-Shuhen specimens are lower than in the...."
M., Kobayashi T., Kobayashi C., Suzuki R., Miyamoto K., Hancock B., Dibden C., and Edmonds J.S. (2004) AMS ${ }^{14} \mathrm{C}$ measurement and preparative techniques at NIES-TERRA. Nuclear Instruments and Methods in Physics Research, B 223-224: 116-123.

Yoneda M., Saso A., Suzuki R., Shibata Y., Morita M., Suwa G., and Akazawa T. (2005) Chronology of the Yayoi skeletal remains from the Kanto district: a preliminary re-evaluation by radiocarbon dating of postcranial material. Anthropological Science, 113: 169-182. 